\title{
AVALIAÇÃO DE VARIÁVEIS OPERACIONAIS DA JIGAGEM DE MINÉRIO DE FERRO POR MEIO DE PLANEJAMENTO ESTATÍSTICO
}

\author{
F. SÃO JOSÉ ${ }^{1}$, H. O. BARCELOS ${ }^{2}$, C. A. PEREIRA ${ }^{3}$ \\ Universidade Federal de Ouro Preto \\ fabio.sao.jose@hotmail.com ${ }^{1}$
}

Artigo submetido em 16/06/2016 e aceito em 24/06/2019

DOI: $10.15628 /$ holos.2019.4724

\section{RESUMO}

A jigagem é uma das técnicas mais antigas para se concentrar minérios no mundo, apropriado para empreendimentos de pequeno a médio porte, além compor, comumente, etapas de pré-concentração em grandes usinas, como uma maneira de se reduzir custos de produção. Dentro desta importante perspectiva da jigagem, foi proposta e realizada uma campanha de testes laboratoriais visando a concentração mineral por jigagem, a fim de avaliar algumas variáveis de influência na concentração de um minério de ferro proveniente do
Quadrilátero Ferrífero (mina de Brucutu). Um planejamento fatorial foi elaborado, o qual constituiu em análise estatística precisa dos experimentos realizados. Por meio da combinação de três variáveis estudadas obteve-se recuperação de ferro igual a $73,14 \%$, com distribuição de sílica de $89,05 \%$ no rejeito e índice de seletividade de 3,80 . Assim, a metodologia permitiu uma avaliação estatística útil e possibilitou contribuir para a tomada de decisões sobre os parâmetros de interesse no processo de jigagem.

PALAVRAS-CHAVE: Planejamento fatorial, Minério de ferro, Recuperação, Quadrilátero Ferrífero.

\section{EVALUATION OF OPERATING VARIABLES OF JIGGING OF IRON ORE BY STATISTICAL PLANNING}

\begin{abstract}
The jigging process is one of the oldest ways used to concentrate ores in the world, suitable for small and medium-sized employability, and is composed of a preconcentration step as a way to reduce costs. Within this perspective, a test campaign for laboratorial mineral concentration was set up, in order to determine the main variables (and their interactions) that may have an influence on the concentration of iron ore from the Iron Quadrangle by the jigging process. A factorial planning
\end{abstract}

was prepared, so that an accurate statistical analysis of experiments could be performed. A combination of the three variables studied (feed granulometry, background layer and bed mass) promoted an iron recovery equal to $73.14 \%$, a distribution of silica of $89.05 \%$ on the tailing and a selectivity index of 3.80 . Thus the methodology enabled a useful statistical evaluation and can contribute to decision-making regarding the parameters of interest in the jigging process.

KEYWORDS: Factorial design, Jigging process, Iron ore, Iron Quadrangle. 


\section{INTRODUÇÃO}

\subsection{Jigagem como pré-concentração de minérios}

O Quadrilátero Ferrífero, localizado na região central de Minas Gerais, é uma das regiões minerárias mais importantes do Brasil, pois possui um dos mais importantes massivos minerais, fonte de ouro, topázio imperial, bauxita, manganês e ferro. Sendo que este último se tornou emblema da atividade primária no Estado.

A concentração gravítica é o método de separação de partículas minerais de diferentes massas específicas. E na maioria dos processos de concentração gravítica, além da gravidade, a resistência à queda oferecida pelo meio é outra força usada. Geralmente utiliza-se a água, um líquido denso, ou mistura de um líquido e partículas sólidas mantidas em suspensão como meio de separação (Gaudin, 1939).

Fazendo parte dos métodos de concentração gravítica, tem-se a jigagem, que opera de maneira cíclica promovendo ciclos que consistem em quatro estágios, denominados entrada, expansão, exaustão e compressão (Mishra \& Mehrotra, 1998). O resultado é a estratificação do leito, que corresponde à separação das partículas em camadas ou estratos de massas específicas crescentes desde o topo até a base (Sampaio \& Tavares, 2005).

Os três maiores efeitos que contribuem com a estratificação de um leito no jigue são: (i) sedimentação forçada, (ii) aceleração diferencial e (iii) consolidação (Mishra \& Mehrotra, 1998).

A sedimentação forçada tem um efeito maior na separação de partículas grosseiras e a aceleração inicial, durante a sedimentação das partículas na suspenção, pode ser devida a um simples balanço de forças, conforme Equação 1:

$$
\left(\frac{d v}{d t}\right)=\left(1-\frac{\rho_{f}}{\rho_{s}}\right) g
$$

Onde $v$ é a velocidade instantânea de sedimentação das partículas, $\rho_{f}$ e $\rho_{s}$ são as massas específicas do fluido e sólido respectivamente, t é o tempo e $g$ a aceleração da gravidade.

A escolha do método físico adequado para a concentração de um minério depende, entre outros fatores, da granulometria de liberação, da propriedade física diferenciadora por meio da qual é possível a separação, do volume do minério a ser processado além do teor de alimentação e da especificação de produtos.

Segundo (Wills, 2006), o processo de jigagem permanece como principal método de préconcentração de minério de ferro e tungstênio e é amplamente utilizado no tratamento de carvão e minério de estanho e muitos outros minerais industriais.

Dentro da perspectiva da utilização de métodos físicos, este trabalho teve como objetivo efetuar uma campanha de ensaios de concentração de minerais em um jigue laboratorial marca $\mathrm{DECO}^{\circledR}$, modelo $\mathrm{A}-173-\mathrm{A}$, visando avaliar as interações de variáveis que podem influenciar na concentração de um minério de ferro proveniente do Quadrilátero Ferrífero. Um planejamento fatorial foi elaborado, com o intuito de se realizar uma análise estatística apurada dos experimentos. 


\subsection{O planejamento estatístico aplicado a experimentos}

Experimentação é uma vital parte no método científico e, certamente existem situações onde fenômenos científicos são tão bem conhecidos que para alcançar resultados usam-se modelos matemáticos, que podem ser desenvolvidos diretamente pela aplicação de princípios físicos.

Porém, em sistemas complexos, como no processamento mineral, geralmente se tomam decisões baseadas em modelos empíricos.

Segundo (Scarminio et al., 2003), no caso especial do processamento mineral, dados gerados em experimentos são parâmetros básicos tanto para implementação de novas rotas, como para parametrização, adequação e otimização de rotas existentes.

Algumas das variáveis de entrada no sistema são controláveis, outras não.

E dentro da experimentação, independentemente de sua complexidade ou não, os objetivos podem se concentrar em:

i- determinar o valor de resposta em função dos valores de entrada;

ii - determinar para quais valores das variáveis influenciais $X^{\prime}$ s o valor da resposta $Y$ se encontra mais perto do desejado;

iii - determinar para quais valores das variáveis influenciais os valores X's de entrada são menores;

iv - determinar para quais valores das variáveis influenciais $X^{\prime} \mathbf{s}$ os efeitos das variáveis incontroláveis Z's são minimizados.

Para explicar os efeitos da interação de dois fatores sobre uma variável resposta pode-se utilizar o chamado algoritmo de Yates inverso, que considera apenas os fatores cuja interação é objetivo da análise. Nesse caso, inverte-se a ordem dos experimentos e a ordem dos valores correspondentes (Martins, 1996).

\subsection{Mina de Brucutu - Vale S/A}

A jazida de minério de ferro denominada Brucutu ocupa uma área de $8 \mathrm{~km}^{2}$ e está situada a nordeste do Quadrilátero Ferrífero, próximo à cidade de São Gonçalo do Rio Abaixo e a aproximadamente $84 \mathrm{~km}$ na direção leste de Belo Horizonte, capital do Estado de Minas Gerais. 0 complexo mineiro de Brucutu engloba 3 áreas denominadas: Brucutu I, II, e III, sendo Brucutu I a que tem a área da mina usualmente chamada de Brucutu. $O$ tratamento do minério na usina de concentração envolve a utilização dos processos de concentração por jigagem, concentração magnética e flotação, de acordo com a distribuição granulométrica. De acordo como (Jesus, 2005) a jigagem foi responsável por $24 \%$ da produção anual da usina de concentração de Brucutu no ano de 2004, dado mais significante já registrado. Dados atualizados não foram compartilhados pela empresa. 


\section{METODOLOGIA}

\subsection{Amostras}

As amostras para realização deste trabalho formam fornecidas pela empresa Vale provenientes da mina Brucutu. Um total de $94,54 \mathrm{~kg}$ foi coletado pela empresa Vale de forma incremental e armazenados em seis sacos plásticos para transporte até ao Laboratório de Tratamento de Minérios (LTM) do Instituto Federal de Minas Gerais (IFMG), onde se seguiram as preparações das amostras.

A preparação iniciou-se pela homogeneização do material recebido e foi feita manualmente pelo método da pazada. Seguiu-se a formação de uma pilha cônica a qual foi posteriormente dividida em duas alíquotas, sendo uma alíquota destinada a peneiramento na faixa de 2,36 a $1 \mathrm{~mm}$ e a segunda alíquota submetida a peneiras de 3,35 a $1 \mathrm{~mm}$. Essas frações granulométricas foram utilizadas nos ensaios de concentração por jigagem.

As massas dos materiais bitolados, em ambas as faixas citadas, foram homogeneizadas por meio de pilhas alongadas e divididas para formação de frações a serem utilizadas nos ensaios propostos.

\subsection{Preparação dos seixos de hematita}

Para a confeç̧ão dos seixos de hematita, material utilizado para compor a camada de fundo do leito no jigue, foi obtido um bloco de hematita compacta da mina de Brucutu. Após cominuição em britador de mandíbulas tipo Blake o material foi classificado por peneiramento entre 19,1 e 12,7 $\mathrm{mm}$ e colocado em regime com esferas de aço de $40 \mathrm{~mm}$ de diâmetro em um moinho tubular por 2,5 horas para redução de arestas nas partículas de hematita. Finalmente, todo volume foi classificado entre 12,7 e 9,52 mm para eliminação das frações mais finas geradas na etapa de redução de arestas. Dessa forma, foi possível gerar seixos de hematita isentos de arestas para a formação da "cama" do leito do jigue.

\subsection{Concentração no jigue}

O jigue da marca $\mathrm{DECO}{ }^{\circledR}$, modelo A-173-A, com seção transversal de dimensões $203 \times 305$ $\mathrm{mm}$, com crivo fixo e impulso de água proporcionado pelo movimento do diafragma foi o equipamento utilizado nos testes de bancada propostos. Para a realização de tais testes o jigue operou com um curso de $260 \mathrm{~mm}$, frequência de 150 golpes por minuto e a água de lavagem com vazão de 9,33 litros por minuto.

Objetivando alcançar condição ótima de concentração do minério de ferro utilizado, foram escolhidas três variáveis para a concentração no jigue: granulometria da alimentação, tipo dos seixos que compõem o leito e a massa do leito.

O intervalo de tamanho de partícula processado em jigues depende do material e do tipo de equipamento. $\mathrm{O}$ material em um primeiro momento foi dividido em duas faixas granulométricas distintas. A primeira, compreendida entre 2,36 e $1 \mathrm{~mm}$, que ficou definida como faixa fina. A segunda, compreendida entre 3,35 e $1 \mathrm{~mm}$, sendo especificada como faixa grossa. Diante disso, 
foram obtidas duas faixas granulométricas a serem estudadas, sendo que faixa granulométrica ficou definida como variável " $A$ ".

Outra variável em estudo é a camada de fundo composta por dois materiais distintos, seixos de hematita e esferas de aço. A camada de fundo é a segunda variável denominada " $\mathrm{B}$ ".

Finalmente, outra variável a ser estudada foi a massa de seixos que formou o leito, ou seja, foi a massa do leito que definiria os números de camadas no fundo do jigue. Adotou-se a massa do leito como variável " $\mathrm{C}$ ".

Logo, a concentração do minério de ferro ficou em função das três variáveis $A, B$ e $C$. Na Tabela 1 tem-se as variáveis selecionadas para o estudo e seus respectivos níveis de trabalho definidos pelo planejamento de experimentos.

Tabela 1: Variáveis selecionadas para o planejamento de experimentos.

\begin{tabular}{c|c|c|c}
\hline & Variáveis & \multicolumn{2}{|c}{ Níveis } \\
\hline A & Granulometria da alimentação & Fina (-) & Grossa (+) \\
\hline B & Camada de fundo & Seixos de hematita (-) & Esferas de aço (+) \\
\hline C & Massa do leito & $250 \mathrm{~g} \mathrm{(-)}$ & $300 \mathrm{~g}(+)$ \\
\hline
\end{tabular}

O planejamento fatorial em dois níveis $\left(2^{\mathrm{k}}\right)$ (Tabela 2) foi escolhido como método, considerando as três variáveis, levando a oitos ensaios diferentes.

Para a avaliação do erro experimental foram feitas as tréplicas desses experimentos, gerando 24 ensaios. A escolha da sequência de execução dos ensaios foi aleatória e seguiu a ordem apresentada na Tabela 2.

Como parâmetros de avaliação da concentração do minério de ferro foram analisados a recuperação metálica e o índice de seletividade, sendo considerados apenas resultados que apresentaram desvio em relação à média abaixo de $10 \%$.

Para as análises químicas foram empregados os métodos de fluorescência de raios $X$ (espectrômetro da marca Philips - PANalytical, modelo MagiX), espectrometria de emissão atômica (espectrofotômetro de emissão óptica com plasma acoplado indutivamente, marca Agilent, modelo 725) e por via úmida, visando os seguintes elementos e/ou compostos químicos: $\mathrm{Fe}_{\text {total }}$ e $\mathrm{SiO}_{2}$.

Tabela 2: Sequência de ensaios para planejamento fatorial em dois níveis.

\begin{tabular}{|c|c|c|c|c|c|c|c|c|}
\hline \multirow{3}{*}{$\stackrel{\mathscr{E}}{\stackrel{\mathscr{N}}{\mathscr{E}}}$} & \multirow{3}{*}{$\frac{\sqrt[n]{1}}{\frac{\sqrt[n]{\pi}}{\frac{\pi}{\pi}}}$} & \multirow{3}{*}{ 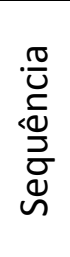 } & \multicolumn{3}{|c|}{ Variáveis } & \multicolumn{3}{|c|}{ Variáveis } \\
\hline & & & A & $B$ & $\mathrm{C}$ & $A$ & $\mathrm{~B}$ & $\mathrm{C}$ \\
\hline & & & $\begin{array}{l}\text { Granulometria } \\
\text { da alimentação }\end{array}$ & $\begin{array}{l}\text { Camada } \\
\text { de fundo }\end{array}$ & $\begin{array}{c}\text { Massa } \\
\text { do } \\
\text { leito }\end{array}$ & $\begin{array}{c}\text { Granulometria } \\
\text { da alimentação } \\
(\mathrm{mm})\end{array}$ & $\begin{array}{l}\text { Camada } \\
\text { de fundo }\end{array}$ & $\begin{array}{c}\text { Massa } \\
\text { do leito } \\
\text { (g) }\end{array}$ \\
\hline 1 & $\mathrm{~T}$ & $8^{\circ}$ & - & - & - & $<2,36$ & hematita & 250 \\
\hline 2 & $A$ & $7^{0}$ & + & - & - & $<3,35$ & hematita & 250 \\
\hline 3 & $B$ & $4^{0}$ & - & + & - & $<2,36$ & aço & 250 \\
\hline 4 & $A B$ & $3^{0}$ & + & + & - & $<3,35$ & aço & 250 \\
\hline 5 & $C$ & $6^{0}$ & - & - & + & $<2,36$ & hematita & 300 \\
\hline 6 & $A C$ & $5^{0}$ & + & - & + & $<3,35$ & hematita & 300 \\
\hline
\end{tabular}




\begin{tabular}{|c|c|c|c|c|c|c|c|c|}
\hline 7 & $B C$ & $2^{\circ}$ & - & + & + & $<2,36$ & aço & 300 \\
\hline 8 & $A B C$ & $1^{0}$ & + & + & + & $<3,35$ & aço & 300 \\
\hline
\end{tabular}

\section{RESULTADOS E DISCUSSÃO}

Uma análise estatística dos resultados, empregando o método fatorial tendo como resposta a recuperação de ferro, foi efetuada com o emprego do software EXCEL ${ }^{\circledR}$. A análise da influência das variáveis e suas interações sobre a resposta experimental foram realizadas com o auxílio do Algoritmo de Yates (Riedwyl, 1998).

\subsection{Análise da recuperação de ferro no concentrado}

A Figura 1 mostra o Gráfico de Pareto referente à recuperação de ferro no concentrado obtido por jigagem. Todos os efeitos que ultrapassaram o valor de 1,86 foram definidos pelo método como significantes. Desta maneira, pode-se confirmar que os fatores $A, C$ e $A B C$, em seus níveis máximos, foi significante numa análise com $90 \%$ de confiança estatística.

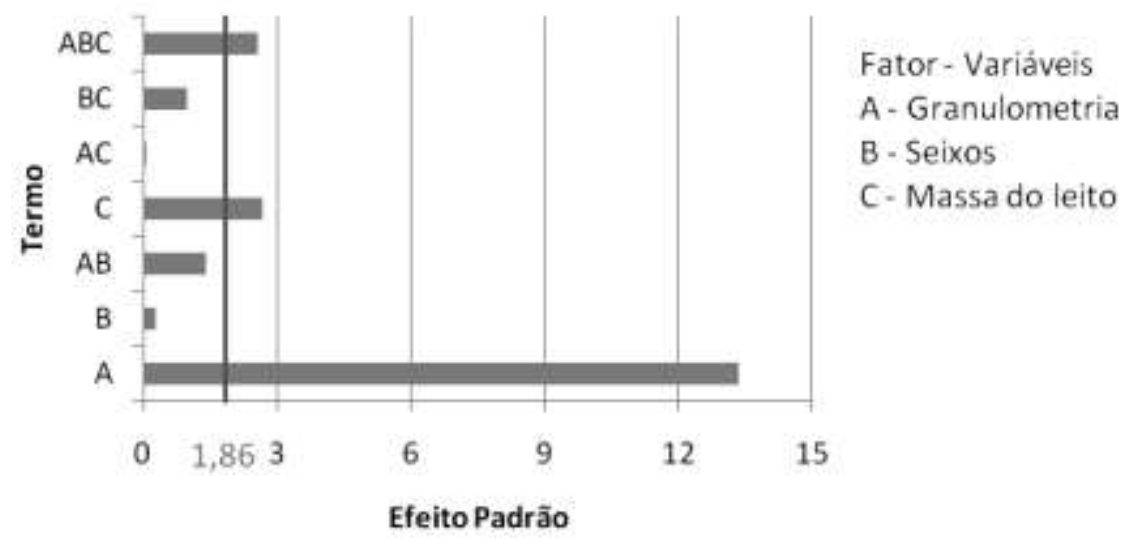

Figura 1: Gráfico de Pareto (Recuperação de Ferro).

A Tabela 3 exibe-se a recuperação de ferro como resposta devida a interação de duas variáveis apenas. A análise foi feita conforme a técnica do algoritmo de Yates, que possibilita a identificação de tais efeitos de interações de variáveis em determinada resposta esperada.

Tabela 3: Resultados para recuperação de ferro [\%] (Algoritmo de Yates)

\begin{tabular}{c|cc|c|cc|c|cc}
\hline & Hematita & Aço & & $250 \mathrm{~g}$ & $300 \mathrm{~g}$ & & $250 \mathrm{~g}$ & $300 \mathrm{~g}$ \\
\hline Grossa & 32,90 & 28,43 & Aço & 52,62 & 43,04 & Grossa & 34,23 & 27,10 \\
Fina & 64,31 & 67,23 & Hematita & 50,80 & 46,41 & Fina & 69,19 & 62,35 \\
\hline
\end{tabular}

É possível verificar que a granulometria da alimentação foi a que mais contribuiu para a recuperação de ferro. Por outro lado, notamos também que a granulometria da alimentação combinada com a variação da massa do leito proporcionou maior recuperação de ferro e igual a $69,19 \%$. 


\subsection{Análise do Índice de Seletividade}

A Figura 2 apresenta o Gráfico de Pareto referente ao índice de seletividade. Todos os efeitos que ultrapassaram o valor de 1,86 foram significantes. Desta maneira, pode-se confirmar que o efeito $A B C$ e o efeito $B C$ foram as combinações das variáveis significativas, numa análise com $90 \%$ de confiança estatística. Podemos observar também que o fator $B$ e o fator $C$ foram as variáveis menos expressivas.

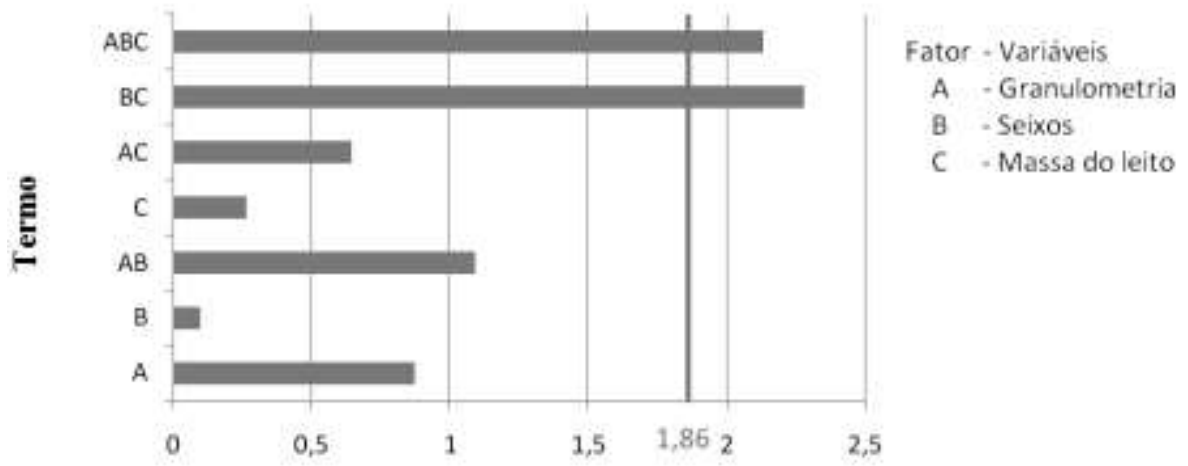

Figura 2: Gráfico de Pareto (Índice de Seletividade)

Através da Tabela 4 é possível identificar que o tipo dos seixos que compõem o leito foi a variável que mais contribui para o índice de seletividade do processo. Notou-se também que a variável seixos do leito apresentaram uma melhor resposta combinada com a variação da granulometria da alimentação.

Tabela 4: Resultados índice de seletividade [-] (Algoritmo de Yates)

\begin{tabular}{c|cc|c|cc|c|cc}
\hline & Hematita & Aço & & $250 \mathrm{~g}$ & $300 \mathrm{~g}$ & & $250 \mathrm{~g}$ & $300 \mathrm{~g}$ \\
\hline Grossa & 3,56 & 3,74 & Aço & 3,79 & 3,40 & Grossa & 3,64 & 3,68 \\
Fina & 3,60 & 3,45 & Hematita & 3,43 & 3,73 & Fina & 3,60 & 3,45 \\
\hline
\end{tabular}

O maior índice de seletividade obtido foi com a interação de esferas de aço com massa de leito de $250 \mathrm{~g}$, atingindo um valor de 3,79\%.

\subsection{Influência das variáveis de operação no desempenho do processo - Diagramas de Cubo}

As Figuras 3, 4 e 5 mostram os efeitos das variáveis granulometria da alimentação, tipo de seixos e massa do leito na recuperação de ferro.

A variação na granulometria da alimentação foi o tópico que obteve maior efeito negativo na recuperação de ferro ao passarmos de tamanhos inferiores a 2,36 $\mathrm{mm}$ para inferiores a 3,35 $\mathrm{mm}$, provocando uma perda média de $35,11 \%$ de ferro. Quando se trabalhou apenas com hematita, a redução média foi de $31,41 \%$ de ferro, enquanto que ao trabalhar exclusivamente com esferas de aço, a perda foi de $38,80 \%$ de ferro em média. 


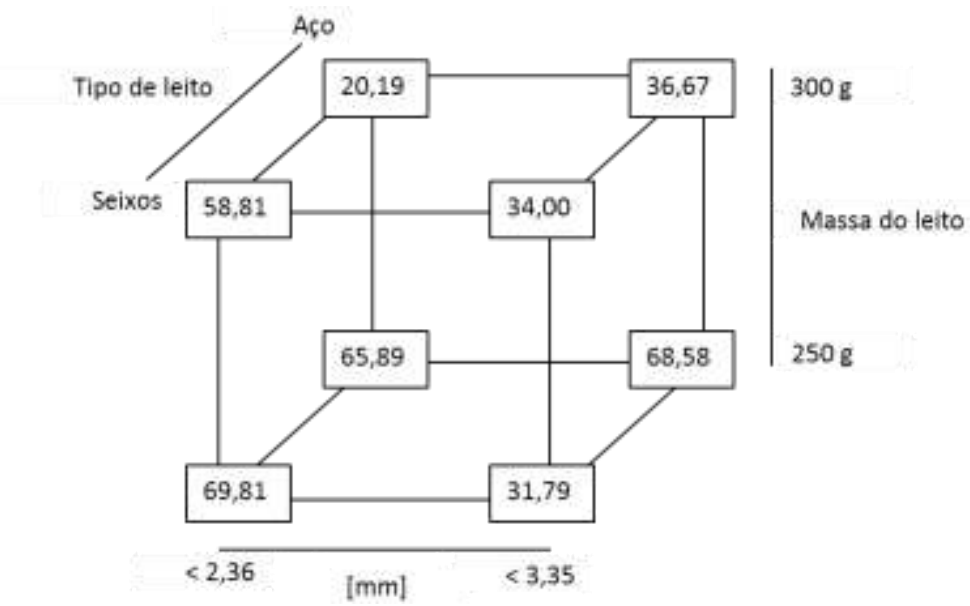

Figura 3: Diagrama para a interpretação dos resultados de recuperação de ferro, valores em \%.

A substituição da camada de fundo, alternando de seixos de hematitas para esferas de aço, foi a variável que apresentou menor efeito na recuperação de ferro, uma perda média de $0,77 \%$ de ferro.

Ao passarmos de $250 \mathrm{~g}$ para $300 \mathrm{~g}$ de seixos, ou seja, com a variação da massa que compõe o leito, obtivemos um decréscimo de $6,03 \%$ de ferro em média.

A maior recuperação de ferro foi de $69,81 \%$ obtido no ensaio 1 com as seguintes condições: granulometria compreendida entre $2,36 \mathrm{~mm}$ e $1 \mathrm{~mm}$, camada de fundo formada por seixos de hematita e operando com massa leito de $250 \mathrm{~g}$.

Na Figura 4 apresenta-se a distribuição de sílica, elemento contaminante do concentrado de ferro e importante de ser analisada. Dessa forma, objetivou-se alcançar a maior distribuição possível de sílica no rejeito.

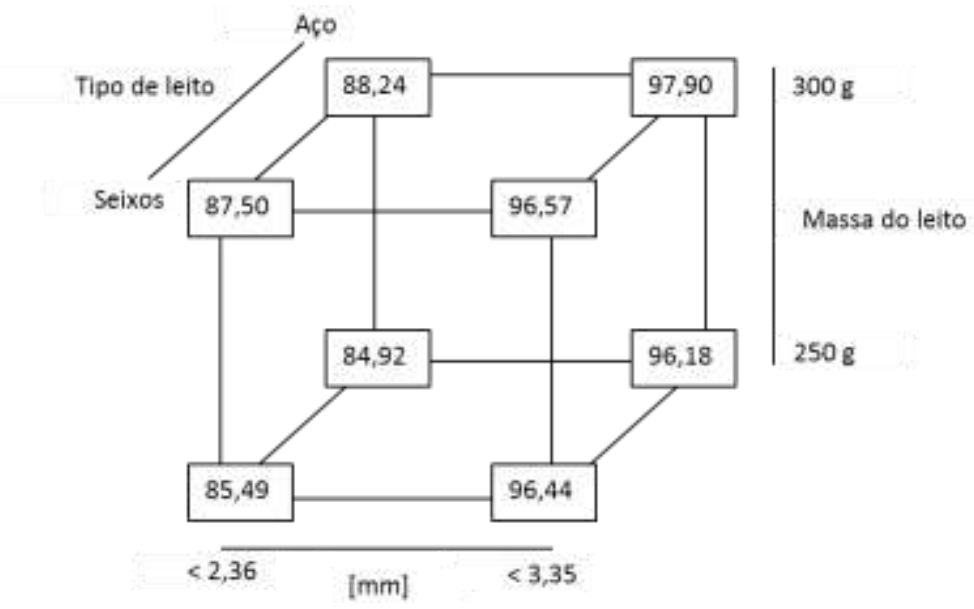

Figura 4: Diagrama para a interpretação dos resultados de distribuição de sílica no rejeito, valores em \%.

O aumento da granulometria de alimentação apresentou efeito favorável, pois ao passar da faixa inferior a 2,36 $\mathrm{mm}$ para abaixo de 3,35 mm, obteve-se acréscimo de 10,24\% de sílica no rejeito. Ao trabalhar apenas com hematita o aumento médio foi de apenas $10,01 \%$ enquanto que o uso exclusivo de esferas de aço alcançou até 10,46\% em média de recuperação de sílica no rejeito.

A substituição do tipo do leito, passando de seixos de hematitas para esferas de aço apresentou efeito positivo de $0,31 \%$ na distribuição de sílica para o rejeito. 
A variação na massa que compôs o leito foi o tópico que também contribuiu positivamente na distribuição de sílica no rejeito, de tal forma que foi notado um acréscimo de 1,79\%.

É importante salientar que a maior distribuição de sílica no rejeito foi de $97,90 \%$, obtido no ensaio 8 onde foi trabalhado com uma granulometria compreendida entre $3,35 \mathrm{~mm}$ e $1 \mathrm{~mm}$, leito formado por esferas de aço e composto por uma massa de $300 \mathrm{~g}$.

A elevação da granulometria, de modo geral, aumentou o índice de seletividade, como mostra a Figura 5, obtendo-se um ganho médio de 0,13\%.

Quando se trabalhou apenas com hematita a perda média foi de $0,033 \%$, enquanto que utilizando-se esferas de aço obteve-se resultado positivo de 0,30\% em média.

A alternância do tipo do leito, passando de seixos de hematitas para esferas de aço, apresentou pequeno efeito positivo no índice de seletividade, com acréscimo médio de $0,01 \%$. É importante salientar que a alternância do tipo de leito produziu efeito positivo de $0,18 \%$ quando se trabalhou com uma faixa granulométrica grossa e por outro lado gerou efeito negativo de $0,15 \%$ quando trabalhou com a faixa granulométrica fina.

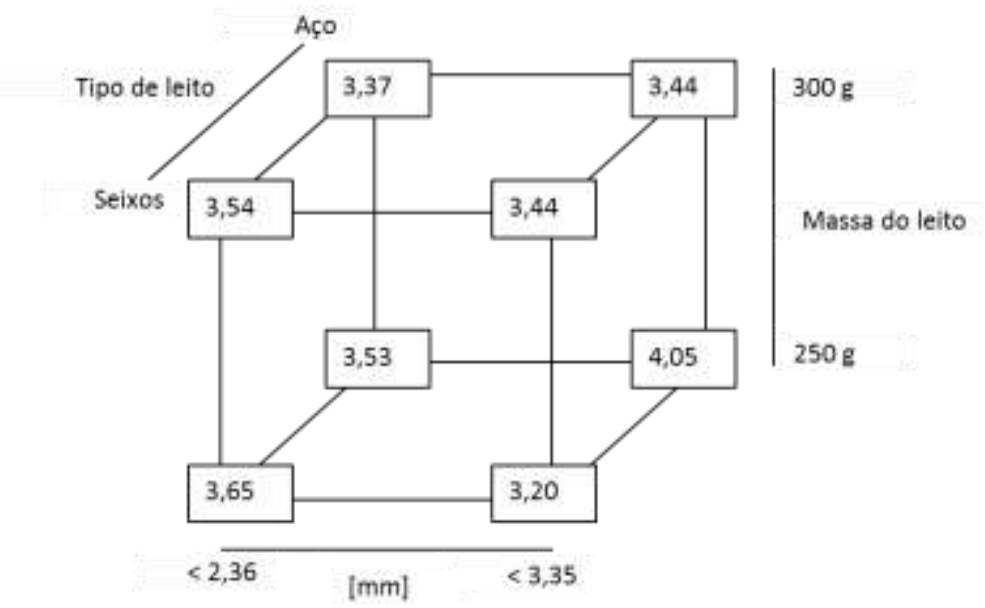

Figura 5: Diagrama para a interpretação dos resultados do Índice de Seletividade.

A alternância do tipo do leito, passando de seixos de hematitas para esferas de aço e aumento da massa do leito levou a uma perda de 0,04\%.

O maior índice de seletividade foi de 4,05 obtido no ensaio 4 com as seguintes condições: granulometria compreendida entre 3,35 e $1 \mathrm{~mm}$, leito composto por $250 \mathrm{~g}$ e formado por esferas de aço.

\section{CONCLUSÕES}

Ficou comprovado que as três variáveis estudadas, granulometria da alimentação, camada de fundo e massa do leito, interagiram entre si interferindo na recuperação de ferro, na distribuição de sílica no rejeito e no índice de seletividade. Pelos resultados obtidos nas condições experimentais estudadas, pode-se concluir o seguinte:

A granulometria da alimentação foi o fator que mais contribuiu para os resultados da recuperação de ferro e na distribuição de sílica, embora (Sampaio \& Tavares, 2005) afirmaram que 
a granulometria da alimentação pode ser a variável de menor influência nos mecanismos de separação quando comparada a outros processos de concentração hidráulica.

O maior enriquecimento de ferro foi de $68,33 \%$ quando operou com granulometria entre 3,35 e $1 \mathrm{~mm}$, leito formado por esferas de aço e massa de leito de $300 \mathrm{~g}$. A melhor recuperação foi de $69,81 \%$ de ferro, trabalhando com uma granulometria compreendida entre 2,36 e $1 \mathrm{~mm}$, leito formado por seixos de hematita e operando com massa de $250 \mathrm{~g}$ no leito.

Analisando a distribuição de sílica obteve-se o melhor resultado trabalhando com granulometria na faixa de 3,35 e $1 \mathrm{~mm}$, utilizando esferas de aço no leito e $300 \mathrm{~g}$ de massa para o mesmo. Sob essas condições foi possível atingir a marca de $97,89 \%$ de sílica no rejeito.

Analisando a seletividade, nas condições estudadas, o maior índice foi de 4,05, obtido com as seguintes condições: granulometria compreendida entre 3,35 e $1 \mathrm{~mm}$, leito composto por $250 \mathrm{~g}$ e formado por esferas de aço.

\section{AGRADECIMENTOS}

Agradecemos à Universidade Federal de Ouro Preto, Fundação Gorceix, CAPES, FAPEMIG, Vale S.A e ao CNPq.

\section{REFERÊNCIAS}

Gaudin, A. M. (1939). Principles of mineral dressing. McGRaw-Hill Book Company Inc.

Mishra, B. K., and Mehrotra, S. P. (1998). Modeling of particle stratification in jigs by the discrete element method, Minerals Engineering, 11(6). 511-522.

Sampaio, C. H., Tavares, L. M. M. (2005). Beneficiamento Gravimétrico: uma introdução aos processos de concentração mineral e reciclagem de materiais por densidade. Porto Alegre: UFRGS Editora.

Wills, B. A. (2006). Mineral Processing Technology: An Introduction to Practical Aspects of ore Treatment and Mineral Recovery. Amsterdam: Elsevier.

Scarminio, I. S., Neto, B. B., Bruns, R. E. (2003). Como fazer experimentos. (2a ed.). Campinas: Editora Unicamp.

Martins, A. H. (1996). Planejamento e análise racional de experimentos tecnológicos. Ipatinga: Usinas Siderúrgicas de Minas Gerais S.A.

Jesus, C. A. G. (2005). Sumário Mineral 2005. Departamento Nacional de Produção Mineral.

Riedwyl, H. (1998). Modifying and using Yates' algorithm. Statistical Papers. 39. 